\title{
Opposing regulation of dopaminergic activity and exploratory motor behavior by forebrain and brainstem cholinergic circuits
}

\author{
Jyoti C. Patel ${ }^{1}$, Elsa Rossignol ${ }^{2, \dagger}$, Margaret E. Rice ${ }^{1} \&$ Robert P. Machold ${ }^{2,3}$
}

Dopamine transmission is critical for exploratory motor behaviour. A key regulator is acetylcholine; forebrain acetylcholine regulates striatal dopamine release, whereas brainstem cholinergic inputs regulate the transition of dopamine neurons from tonic to burst firing modes. How these sources of cholinergic activity combine to control dopamine efflux and exploratory motor behaviour is unclear. Here we show that mice lacking total forebrain acetylcholine exhibit enhanced frequency-dependent striatal dopamine release and are hyperactive in a novel environment, whereas mice lacking rostral brainstem acetylcholine are hypoactive. Exploratory motor behaviour is normalized by the removal of both cholinergic sources. Involvement of dopamine in the exploratory motor phenotypes observed in these mutants is indicated by their altered sensitivity to the dopamine D2 receptor antagonist raclopride. These results support a model in which forebrain and brainstem cholinergic systems act in tandem to regulate striatal dopamine signalling for proper control of motor activity.

\footnotetext{
${ }^{1}$ Department of Neurosurgery, Physiology and Neuroscience, New York, New York 10016, USA. ${ }^{2}$ Smilow Neuroscience Program, New York, New York 10016 USA. ${ }^{3}$ Department of Otolaryngology, NYU School of Medicine, New York, New York 10016, USA. † Present address: Pediatric Neurology, Centre Hospitalier Universitaire Ste-Justine, Montreal, Quebec, Canada. Correspondence and requests for materials should be addressed to R.P.M.

(email: robert.machold@nyumc.org) or to M.E.R. (email: margaret.rice@nyu.edu).
} 
$\mathrm{D}$ opamine (DA) transmission has been implicated in a variety of motor, emotional and cognitive functions ${ }^{1-3}$. Midbrain DA neurons in the substantia nigra pars compacta $(\mathrm{SNc})$ and ventral tegmental area (VTA) provide important modulatory input to the striatal complex, including the caudate putamen $(\mathrm{CPu})$ and nucleus accumbens (NAc). Acetylcholine $(\mathrm{ACh})$ signalling pathways regulate DA efflux within the striatum at two fundamental levels of the circuit ${ }^{4}$. First, the burst firing of DA neurons in the SNc and VTA is stimulated perisomatically by glutamatergic and cholinergic inputs from the pedunculopontine tegmental (PTg) and laterodorsal tegmental (LDTg) nuclei in the rostral brainstem ${ }^{5-7}$, thereby resulting in increased striatal DA efflux ${ }^{6}$ and locomotor activity ${ }^{8}$. In particular, cholinergic inputs from the LDTg appear to act as a gate for the transition from tonic to burst firing modes, thereby regulating the responsiveness of DA neurons to glutamatergic signalling. Second, ACh release from striatal cholinergic interneurons can trigger DA release via presynaptic nicotinic $\mathrm{ACh}$ receptors (nAChRs) on DA axons ${ }^{10-12}$. Inhibition or desensitization of nAChRs on DAergic axons in striatal slices leads to a decrease in DA release evoked by a single stimulus pulse, but an increase in release evoked at burst-like frequencies, thus amplifying the frequency dependence of axonal DA release as monitored by fast-scan cyclic voltammetry ${ }^{13,14}$.

Although striatal ACh can also affect the excitability of medium spiny neurons directly by signalling through muscarinic ACh receptors $(\mathrm{mAChRs})^{15}$, intrastriatal injections of scopolamine, a $\mathrm{mAChR}$ antagonist, does not alter motor activity ${ }^{16}$. In addition to local cholinergic regulation of DA efflux within the striatum, $\mathrm{ACh}$ arising from projection neurons within the ventral forebrain (for example, nucleus basalis of Meynert) likely regulates striatal DA efflux indirectly via modulation of descending glutamatergic pathways from the prefrontal cortex, ventral pallidum and hippocampus to the $\mathrm{SNc} / \mathrm{VTA}^{17,18}$. Thus, we hypothesized that broad removal of ACh within the forebrain would result in exaggerated striatal DA signalling and altered motor behaviours in a manner dependent on the stimulation of burst firing of midbrain DA neurons by brainstem-derived ACh.

To test the relative contributions of forebrain and brainstem cholinergic input to the regulation of DAergic activity, we took advantage of genetic ablation strategies in mice to eliminate ACh synthesis selectively in the forebrain, brainstem, or both regions simultaneously. We then assessed the effects on evoked striatal DA release in vitro, and the behavioural propensity for open field exploration when placed in a novel environment, which is highly responsive to changes in striatal DA efflux ${ }^{19,20}$. We found that mice lacking forebrain $\mathrm{ACh}$ showed enhanced phasic-to-tonic DA release throughout the striatal complex, and exhibited locomotor hyperactivity in a novel environment. By contrast, exploratory motor behaviour was reduced in mice lacking brainstem ACh, consistent with a predicted decrease in DA neuron burst firing, with lower striatal DA signalling indicated by a lack of sensitivity to the DA D2 receptor antagonist raclopride. Remarkably, exploratory motor behaviour was normalized in mice lacking both forebrain and brainstem $\mathrm{ACh}$. These findings highlight the critical roles that forebrain and brainstem cholinergic systems have in driving striatal DAergic activity for the control of exploratory motor activity.

\section{Results}

Generation of forebrain ACh knockout mice. The enzyme choline acetyltransferase (ChAT) is essential for ACh synthesis. To generate animals with a forebrain-restricted ablation of $\mathrm{ACh}$ production, we combined a conditional floxed allele of ChAT $\left(C h A T^{f l o x}\right)^{21}$ with an Nkx2.1 Cre transgenic line in which cumulative recombination is restricted to the forebrain and hypothalamus $^{22}$ (Fig. 1a,b). Using an antisense cRNA probe directed against the floxed exons, we performed in situ hybridization for ChAT mRNA on cryosections prepared from nonmutant transgenic control (see Methods) and ChAT forebrain knockout (KO; Nkx2.1 ${ }^{\text {Cre }}$; ChAT flox/flox; 'forebrain KO') brains at P30. These analyses revealed almost complete elimination of ChAT expression from striatal cholinergic interneurons, with only $6 \pm 3$ ChAT-positive cells in a representative set of forebrain $\mathrm{KO}$ striatal sections that spanned the rostrocaudal extent of the striatum (seven sections from each of three brains) versus $442 \pm 18$ ChAT-positive cells in comparable sections from control brains (seven sections from each of three brains) (Fig. 1c,d). Similar efficacy of ChAT removal was also observed in the medial septum, diagonal band and nucleus basalis (Fig. 1e,f); cortical cholinergic interneurons were not affected as this VIP ${ }^{+}$population does not arise from an $N k \times 2.1$ expressing lineage ${ }^{22}$. Importantly, $N k \times 2.1^{\text {Cre }}$ does not affect ChAT expression in the brainstem of ChAT flox/flox animals (Fig. 1g,h).

Increased phasic-to-tonic DA release in forebrain ACh KO mice. We next examined the consequences of loss of forebrain cholinergic transmission on local DA release regulation using fast-scan cyclic voltammetry to monitor evoked extracellular DA concentration $\left([\mathrm{DA}]_{\mathrm{o}}\right)$ in the dorsolateral region of the $\mathrm{CPu}$ in striatal slices. Release was evoked by either a single-pulse (1 p) stimulation that mimics one action potential or by brief five-pulse $(5 \mathrm{p})$, phasic stimulation at varying frequencies. Consistent with previous pharmacological evidence that endogenous striatal ACh facilitates tonic DA release ${ }^{13,14}$, peak $[\mathrm{DA}]_{\mathrm{o}}$ evoked by $1 \mathrm{p}$ or by $5 \mathrm{p}$ at low frequencies $(\leq 10 \mathrm{~Hz})$ was decreased in forebrain $\mathrm{KO}$ slices compared with control slices (Fig. 2a,b). However, peak $[D A]_{o}$ evoked by high frequency $(100 \mathrm{~Hz})$ stimulation was dramatically higher in the forebrain $\mathrm{KO} \mathrm{CPu}$ (Fig. 2a,b). To establish whether the contrast between phasic-to-tonic DA release differed in control versus forebrain $\mathrm{KO}$ mice, we determined the ratio of $5 \mathrm{p}$ evoked $[\mathrm{DA}]_{\mathrm{o}}$ to that evoked by $1 \mathrm{p}$ at individual DA release sites; comparison of $5 \mathrm{p}$-to- $1 \mathrm{p}$ ratios also normalized differences in absolute evoked $[\mathrm{DA}]_{\mathrm{o}}$ between recording sites. These data revealed a marked frequency dependence of DA release in the forebrain $\mathrm{KO} \mathrm{CPu}$ that was absent in slices from control animals $(P<0.001$ at 25,50 and $100 \mathrm{~Hz}$ in forebrain $\mathrm{KO}$ versus control, two-way analysis of variance (ANOVA), Bonferroni correction, $n=16-18$ recording sites from four to five mice per group) (Fig. 2c). The pattern of increased frequency responsiveness of DA release mirrored that seen in control slices when nAChRs were blocked by mecamylamine $(5 \mu \mathrm{M})$ or desensitized by nicotine $(500 \mathrm{nM})$ (Fig. 2c). Moreover, in contrast to the effects seen in control slices, neither mecamylamine nor nicotine had a significant effect on $[D A]_{o}$ evoked by either tonic or phasic $(>10 \mathrm{~Hz}$ ) stimulation (Fig. 2c,d), demonstrating the complete absence of nAChR-dependent regulation of DA release in the $\mathrm{CPu}$ of forebrain $\mathrm{KO}$ animals.

Given differential regulation of DA release in dorsal and ventral striatum by ACh acting at nAChRs and $\mathrm{mAChRs}{ }^{23-25}$, we examined patterns of evoked $[D A]_{o}$ in the NAc core and shell to address whether enhancement in phasic-to-tonic DA signalling in forebrain $\mathrm{KO}$ mice occurred throughout the dorsoventral extent of the striatal complex. Peak evoked $[\mathrm{DA}]_{\mathrm{o}}$ by $1 \mathrm{p}$ was lower in $\mathrm{NAc}$ core and shell than in $\mathrm{CPu}$ in control mice, with $\mathrm{CPu}>\mathrm{NAc}$ core $>$ NAc shell $(P<0.001 \mathrm{CPu}$ versus NAc shell, one-way ANOVA, Bonferroni correction, $n=16$ sites from four mice for $\mathrm{CPu}, n=9$ sites from three mice for NAc core and shell). Also differing from $\mathrm{CPu}$, both NAc core and shell exhibited bellshaped frequency response curves with $5 \mathrm{p}$ stimulation (Fig. 3), as 


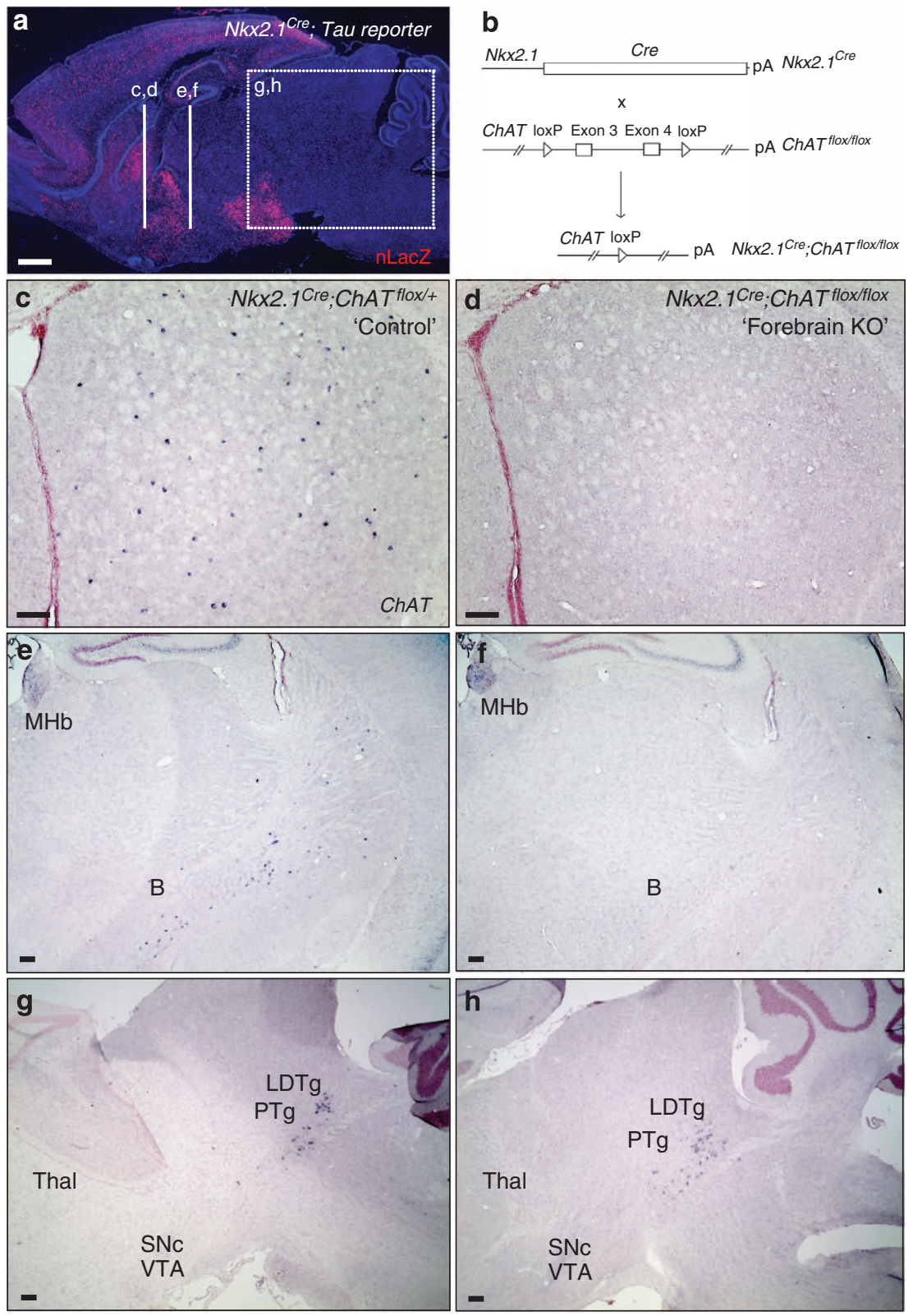

Figure 1 | Genetic strategies for targeted ablation of ACh production in the forebrain. (a) Sagittal field of a P21 Nkx2.1 Cre; TauloxP-stop-loxP-mGFPiresNLSLacZ ('Tau reporter') mouse brain illustrating the populations ( $n L a c Z^{+}$; red) that arise from Nkx2.1 expressing lineages. (b) Genetic strategy for selective elimination of ACh production within the forebrain (Nkx2.1 lineages). (c,d) In situ hybridization for ChAT mRNA in coronal striatal brain cryosections from

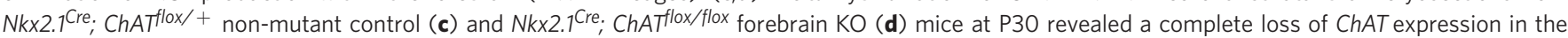

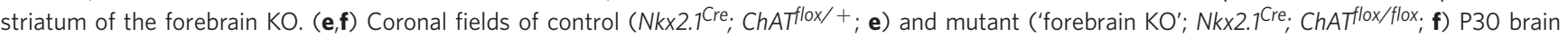
sections stained by in situ hybridization for ChAT mRNA illustrate the removal of ChAT expression within the nucleus basalis, in addition to the striatum (c, d) and other ventral forebrain cholinergic populations. (g,h) ChAT expression within the rostral brainstem (for example, PTg, LDTg) is not affected in the forebrain KO. Scale bar in a represents $1 \mathrm{~mm}$; scale bars in $\mathbf{c}-\mathbf{h}$ represent $300 \mu \mathrm{m}$. B, nucleus basalis of Meynert; LDTg, laterodorsal tegmental nucleus; $\mathrm{MHb}$, medial habenular nucleus; PTg, pedunculopontine nucleus; Thal, thalamus; VTA, ventral tegmental area.

reported previously ${ }^{23,24,26,27}$. Nevertheless, DA release evoked by $1 \mathrm{p}$ or low-frequency $5 \mathrm{p}$ stimulation was lower than in control mice in the NAc of forebrain KO mice (Fig. 3a,b,d,e). By contrast, release evoked by high frequency stimulation was enhanced in both NAc subregions of forebrain KO mice (Fig. 3a,b,d,e), resulting in a marked amplification of phasic-to-tonic DA signalling at frequencies $>10 \mathrm{~Hz}(P<0.001$ at 25,50 and $100 \mathrm{~Hz}$ in forebrain $\mathrm{KO}$ versus control, two-way ANOVA, Bonferroni correction, $n=9-14$ recording sites from three mice per group) (Fig. 3a,c,d,f). These data confirm the loss of DA release regulation by endogenous $\mathrm{ACh}$ throughout the striatal complex of forebrain $\mathrm{KO}$ mice.

Generating brainstem and double forebrain/brainstem ACh KO mice. Using a similar genetic approach to that used to produce forebrain ChAT KO mice, we generated rostral brainstem ChAT KO animals using the En1 ${ }^{C r e}$ driver $^{28}$, whose cumulative recombination is restricted to the mes/r1 embryonic territory (Fig. 4a,b), and as such, primarily affects the PTg and LDTg but 
a
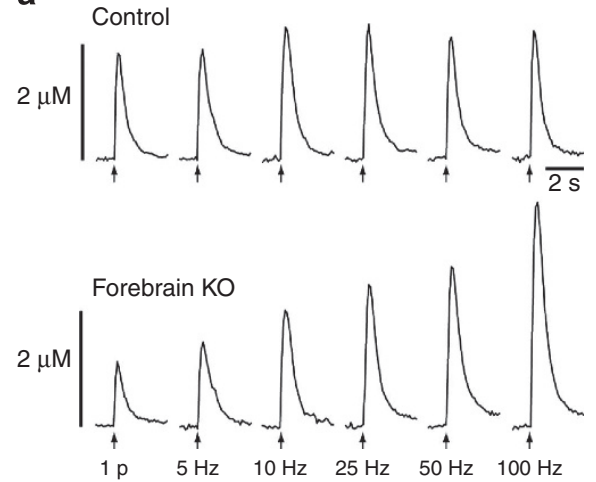

b

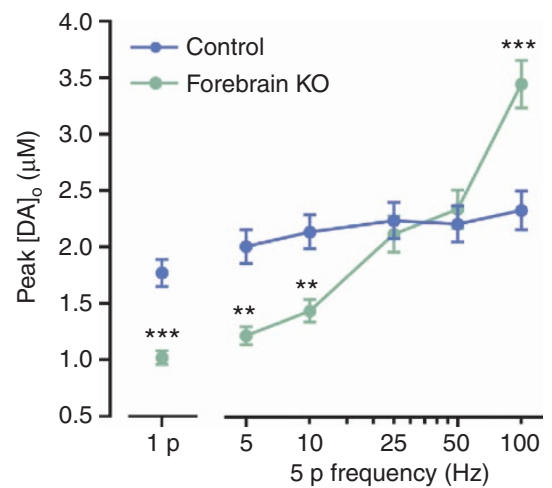

c

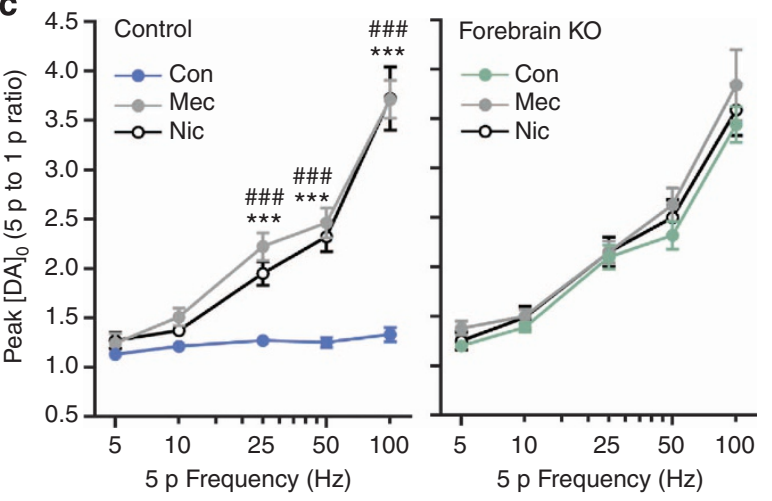

d

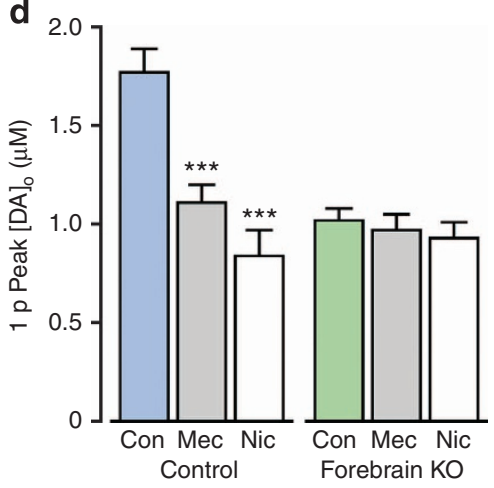

Figure 2 | Loss of forebrain ACh production results in enhanced phasic-to-tonic DA signalling within the dorsal striatum. (a-d) Voltammetric monitoring of extracellular $[D A]_{0}$ in the CPu of striatal slices. (a) Representative single-pulse (1 p) and five-pulse (5 p) evoked [DA]。 recorded in control and forebrain $\mathrm{KO}$ mice. (b) Mean peak [DA $]_{0}$ evoked by $1 \mathrm{p}$ and $5 \mathrm{p}$ stimulation in each group shows suppression of DA release up to $10 \mathrm{~Hz}$, maintenance of release levels at 25 and $50 \mathrm{~Hz}$, and enhanced peak $[D A]_{0}$ at $100 \mathrm{~Hz}\left({ }^{\star \star} P<0.01\right.$; ${ }^{\star \star \star} P<0.001$ versus control; unpaired $t$-test for comparison of $1 \mathrm{p}$ or twoway ANOVA with Bonferroni correction for comparison of 5 p). (c) Frequency dependence ( 5 p-to- 1 p ratio) of evoked [DA]。 in control and forebrain KO mice under control conditions (con) and in the presence of the $\mathrm{nAChR}$ antagonist mecamylamine (mec; $5 \mu \mathrm{M}$ ) or a desensitizing concentration of the

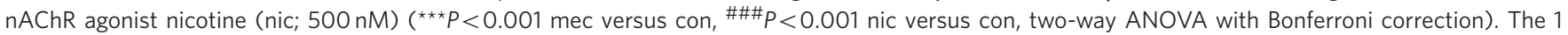
p-to- 5 p ratios in forebrain $\mathrm{KO}$ mice under control conditions were indistinguishable from those in control mice in mec or nic $(P>0.05$ for each frequency for either mec or nic, two-way ANOVA with Bonferroni correction). (d) $1 \mathrm{p}$ evoked [DA] in forebrain KO mice, unlike in control mice, was not suppressed by either mec or nic ( ${ }^{\star \star} P<0.001$ versus con, one-way ANOVA with Dunnett's correction). Control data are from four mice with $n=16$ recording sites in control conditions and $n=8$ sites in each drug. Data for forebrain KOs are from five mice with $n=18$ recording sites in control conditions and $n=9$ sites in each drug. All data are means \pm s.e.m. con, control conditions; mec, mecamylamine; nic, nicotine.

not brainstem motor nuclei that arise from more caudal regions (for example, Mo5) (Fig. 4c,d,g). ChAT brainstem KO mice (En1 ${ }^{\text {Cre }}$; ChAT flox/flox; 'brainstem KO') had no ChAT-positive cells remaining in the rostral brainstem as determined by in situ hybridization in a representative set of sections, whereas control mice had $234 \pm 10$ ChAT-positive cells in comparable fields $(n=3$ brains for each genotype, five comparable sections spanning the $\mathrm{PTg} / \mathrm{LDTg}$ region counted per brain) (Fig. 4c,d). Demonstrating the regional segregation of this ablation strategy, striatal ChAT expression in brainstem $\mathrm{KO}$ mice did not differ from that in control mice (Fig. 4e,f). We then combined these two conditional $\mathrm{KO}$ strategies and generated forebrain/brainstem ACh 'double KO' mice.

$\mathrm{DA}$ release in brainstem and forebrain/brainstem $\mathrm{ACh} \mathrm{KO}$ mice. To confirm that local cholinergic regulation of striatal DA was functionally intact in brainstem $\mathrm{KO}$ mice, we examined the frequency dependence of evoked DA release in striatal slices from these animals. Patterns of $1 \mathrm{p}$ and $5 \mathrm{p}$ evoked $[\mathrm{DA}]_{\mathrm{o}}$ in the $\mathrm{CPu}$ of these animals did not differ from those in control mice (Fig. 5a,b), and were as sensitive as controls to nAChR antagonism by mecamylamine or by nicotine-induced desensitization (Fig. 5c,d). These in vitro data demonstrate that there is no alteration in local cholinergic regulation of striatal DA release or other compensatory changes in response to the chronic loss of brainstem ACh. We then examined DA release in striatal slices from double $\mathrm{KO}$ mice. As in forebrain $\mathrm{KO}$ mice, $1 \mathrm{p}$ evoked $[\mathrm{DA}]_{\mathrm{o}}$ in the $\mathrm{CPu}$ was lower in double $\mathrm{KO}$ versus control mice with enhanced phasic-totonic DA release, and concomitant loss of effect of mecamylamine and nicotine on evoked $[\mathrm{DA}]_{\mathrm{o}}$ (Fig. 5). These data confirm the functional loss of forebrain ACh in double $\mathrm{KO}$ mice, as seen in forebrain $\mathrm{KO}$ mice. Of course, in these in vitro experiments the pattern of stimulation is experimenter driven, whereas in vivo the pattern will be determined by DA neuron firing activity that then undergirds striatal DA release ${ }^{29}$ and its consequent influence on motor behaviour.

Locomotor behaviour of $\mathrm{ACh} \mathrm{KO}$ mice in a novel environment. To test the behavioural consequences arising from the total loss of forebrain and or brainstem cholinergic regulation, we evaluated 
a
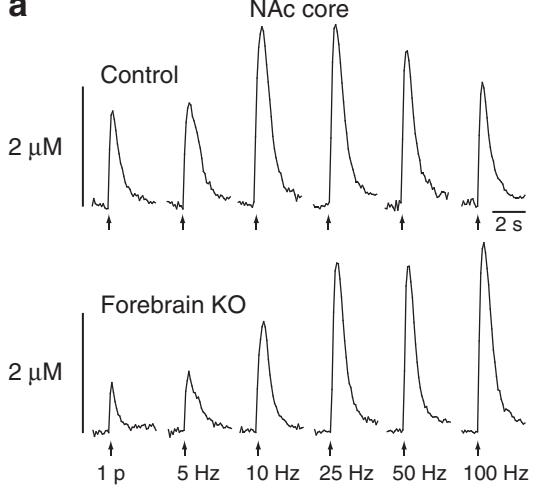

d
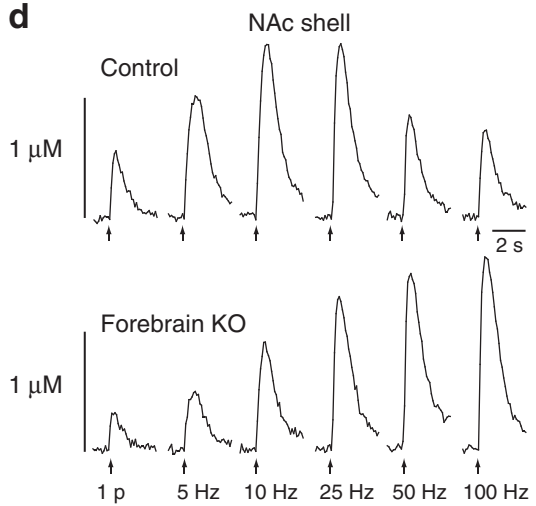

b

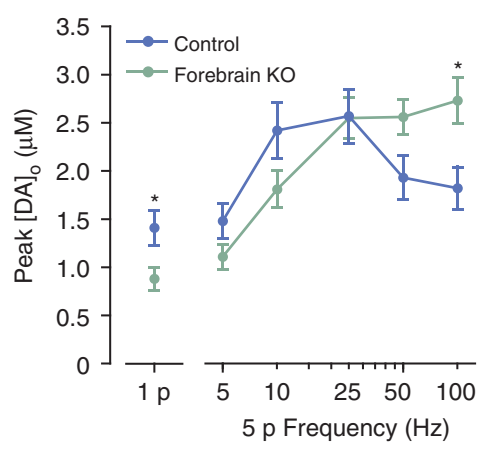

e

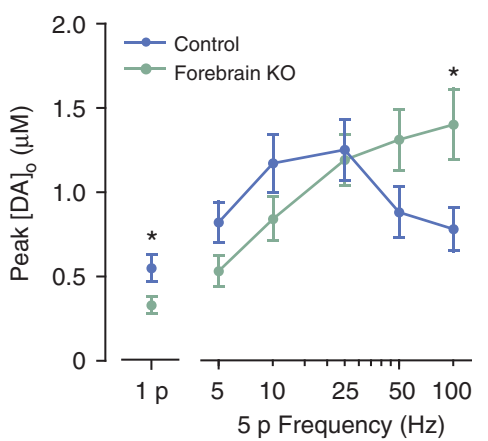

C

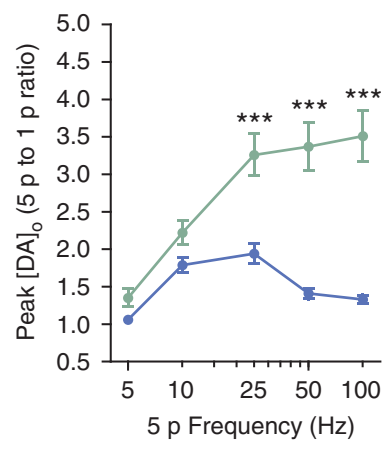

f

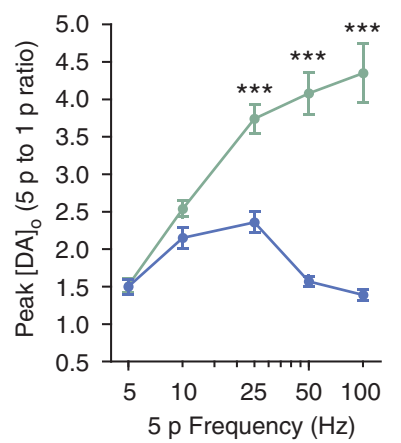

Figure 3 | Loss of forebrain Ach production results in enhanced phasic-to-tonic DA signalling within the ventral striatum. (a-f) Voltammetric monitoring of extracellular $[D A]_{0}$ in the NAc of striatal slices. (a,d) Representative single-pulse (1 p) and five-pulse (5 p) evoked [DA]。 recorded in nonmutant control and forebrain KO mice in the NAc core (a) and NAc shell (d). (b,e) Mean peak [DA]。 evoked by $1 \mathrm{p}$ and $5 \mathrm{p}$ stimulation in each group shows suppression of DA release up to $10 \mathrm{~Hz}\left({ }^{\star} P<0.05\right.$ versus control for $1 \mathrm{p}$; unpaired $t$-test or two-way ANOVA with Bonferroni correction for comparison of $5 \mathrm{p}$ ), maintenance of release levels at $25 \mathrm{~Hz}$ and enhanced peak $[D A]_{0}$ at 50 and $100 \mathrm{~Hz}\left({ }^{\star} P<0.05\right.$ versus control for $100 \mathrm{~Hz}$; two-way ANOVA with Bonferroni correction) in both the NAc core (b) and NAc shell (e). (c,f) Frequency dependence (5 p-to-1 p ratio) of evoked [DA]。 in control and forebrain $\mathrm{KO}$ mice under control conditions. The $1 \mathrm{p}$-to- $5 \mathrm{p}$ ratios in forebrain $\mathrm{KO}$ mice were enhanced at frequencies above $25 \mathrm{~Hz}\left({ }^{\star \star \star} \mathrm{P}<0.001\right.$ for each frequency, two-way ANOVA with Bonferroni correction) in both the NAc core (c) and NAc shell (f) indicating enhanced phasic-to-tonic DA signalling throughout the ventral striatum with loss of ACh. Data for NAc core are from three control mice and three forebrain KOs with $n=14$ recording sites in each. Data for NAc shell are from three control mice with $n=9$ recording sites and three forebrain KOs with $n=11$ recording sites. All data are means \pm s.e.m.

the locomotor behaviour of naive mice in the novel environment of the open field arena, which is linked to burst firing of DA neurons and consequent DA release ${ }^{19,20,30,31}$. Forebrain KO mice were hyperactive and hyperkinetic in that the total distance travelled during the first $10 \mathrm{~min}$ in the arena was significantly greater than that of non-mutant littermate control mice (Fig. 6a), and the movement velocity was enhanced (Fig. 6b). To assess the DA dependence of open field activity, we administered the competitive D2 receptor antagonist raclopride, whose displacement is commonly used as an index of DA release in human PET studies $^{32,33}$. We found that raclopride was effective at suppressing total locomotor activity in forebrain KO mice, but only at a higher dose $\left(>0.25 \mathrm{mg} \mathrm{kg}^{-1}\right)$ than that necessary to decrease activity in control mice (Fig. 6d). The decreased efficacy of low-dose raclopride in forebrain $\mathrm{KO}$ mice argues against a role for increased receptor sensitivity from decreased tonic DA release as a contributing factor in the motor response. Instead, these data indicate elevated $[\mathrm{DA}]_{\mathrm{o}}$ at postsynaptic D2 receptors on striatal output neurons in these animals, when placed in a novel environment, and are consistent with the increase in phasic versus tonic striatal DA efflux observed in response to phasic stimulation in vitro (Figs 2 and 3 ).

Considering that brainstem cholinergic inputs regulate the transition of midbrain DA neurons from tonic to burst firing modes $^{9}$, we next examined the effects of removing these brainstem ACh signalling pathways on exploratory behaviour in the novel environment of the open field arena (Fig. 6). Brainstem $\mathrm{KO}$ animals exhibited significantly less exploratory activity in the open field and were hypokinetic compared with control mice (Fig. 6a,b). As the removal of ChAT was restricted to the rostral brainstem, this hypoactivity was not due to loss of cholinergic activity from motor neurons in the hindbrain or spinal cord (Fig. 4c,d,g). These data are consistent with the expected decrease in phasic DA neuron firing with loss of brainstem cholinergic input. Indeed, raclopride had little effect on exploratory motor activity, even at the higher dose (Fig. 6d), thereby suggesting lower burst-driven D2 receptor activation in these animals than in control mice. Remarkably, the exploratory activity of animals lacking both forebrain- and brainstem-derived ACh was normalized to that of non-mutant control mice (mean distance travelled, $P>0.05$ versus control) (Fig. 6a), as was the velocity of movement ( $P>0.05$ versus control) (Fig. $6 \mathrm{~b})$. Thus, the enhanced phasic-to-tonic striatal DA release in these mice can compensate for the diminished burst output of midbrain DA neurons arising from the loss of brainstem cholinergic signalling, resulting in normal motor output. Consistent with a key role for burst-driven D2 receptor activation during exploration of a novel environment, double KO mice showed similar insensitivity to raclopride 

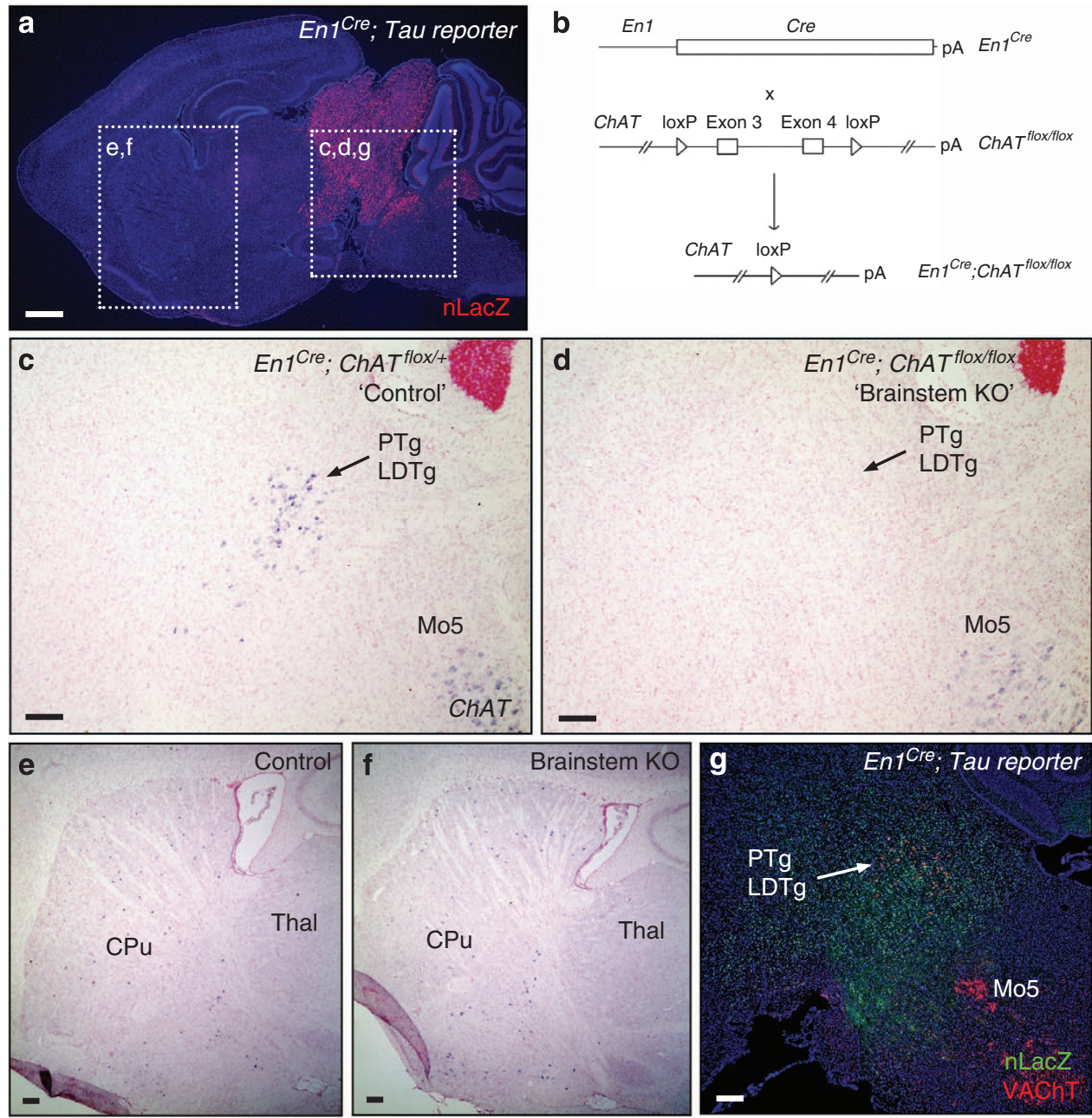

Figure 4 | Genetic strategies for targeted ablation of ACh production in the rostral brainstem. (a) Sagittal field of a P21 En7 $7^{C r e}$; TauloxP-stop-loxPmGFPiresNLSLacZ ('Tau reporter') mouse brain illustrating the populations ( $n$ LacZ ${ }^{+}$; red) that arise from En1 expressing lineages. (b) Genetic strategy for selective elimination of ACh production within the rostral brainstem (En1 lineages). (c, d) In situ hybridization for ChAT mRNA in sagittal brainstem cryosections from En7 Cre, ChATflox/+ non-mutant control (c) and En7 ${ }^{C r e}$; ChATflox/flox brainstem KO (d) mice at P3O revealed a complete loss of ChAT expression in the PTg/LDTg of the brainstem KO, but normal ChAT expression in Mo5. (e, f) Sagittal fields of control (En7 Cre, ChATflox/ +; e) and mutant ('brainstem KO'; Ent Cre, ChAT flox/flox; f) P30 forebrain sections stained by in situ hybridization for ChAT mRNA reveals normal ChAT expression in the forebrain of brainstem KO mice. (g) Sagittal field of a P21 En7 Cre; Tau reporter brain section stained by immunohistochemistry for nuclear $\beta$-galactosidase (nLacZ; green) and vesicular acetylcholine transporter (VAChT; red) reveals complete labelling of the PTg/LDTg but no labelling within Mo5. Scale bar in a represents $1 \mathrm{~mm}$; scale bars in $\mathbf{c - g}$ represent $300 \mu \mathrm{m}$. CPu, caudate putamen; LDTg, laterodorsal tegmental nucleus; Mo5, motor trigeminal nucleus; PTg, pedunculopontine nucleus; Thal, thalamus.

to that seen in brainstem $\mathrm{KO}$ animals (Fig. 6d). We did not find any difference across genotypes in the ratio of time spent in the centre versus perimeter zones of the open field arena during the $10 \mathrm{~min}$ of testing (Fig. 6c), indicating that anxiety-related behaviour changes were not a contributing factor to the differences in exploration observed across the genotypes.

\section{Discussion}

We show here that loss of forebrain ACh leads to increased phasic-to-tonic DA signalling throughout the striatal complex and hyperactivity in contexts that stimulate brainstem ACh activity and burst firing of DA neurons (for example, a novel environment), whereas loss of brainstem ACh leads to hypoactivity under similar conditions. Nevertheless, the striatum does not work in isolation, so that it is likely that the behaviour observed in our forebrain KOs is a synthetic phenotype arising from the total removal of forebrain $\mathrm{ACh}$, with consequent alterations in the activities of descending glutamatergic projections from the prefrontal cortex, ventral pallidum and hippocampus that converge upon the SNc/VTA. Overall, our results support a model in which brainstem cholinergic inputs to midbrain DA neurons provide key regulation of the transition from tonic to burst firing modes that is then stimulated by diverse glutamatergic inputs ${ }^{34}$, with independent regulation of axonal DA release probability in the striatum by cholinergic interneurons signalling through nAChRs (Fig. 6e).

A number of studies have examined the role of forebrain cholinergic neurons (striatal and projection) in regulating motor activity; however, to date the overall conclusion remains unclear. Complete loss of cholinergic cells in the NAc leads to hyperactivity $^{35}$, whereas disruption of ACh neurotransmission via genetic ablation of the vesicular ACh transporter $(V A C h T)$ in all striatal interneurons does not change spontaneous locomotor 


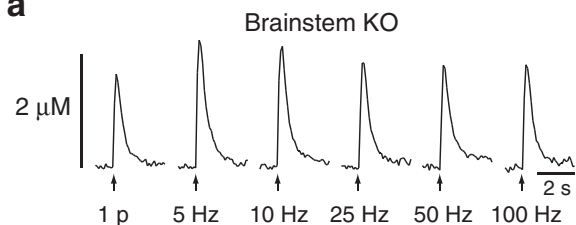

$\begin{array}{llllll}1 \mathrm{p} & 5 \mathrm{~Hz} & 10 \mathrm{~Hz} & 25 \mathrm{~Hz} & 50 \mathrm{~Hz} & 100 \mathrm{~Hz}\end{array}$

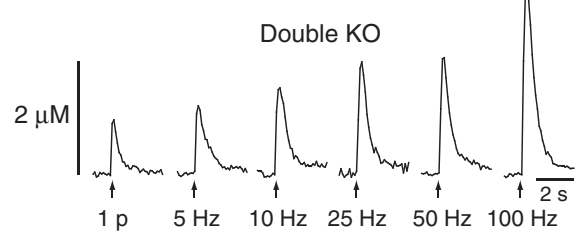

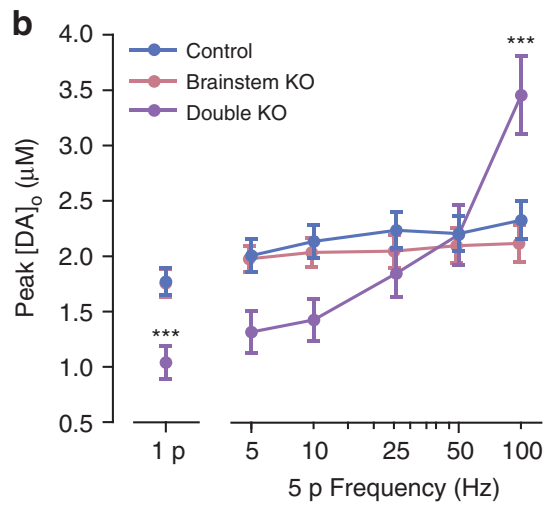

d

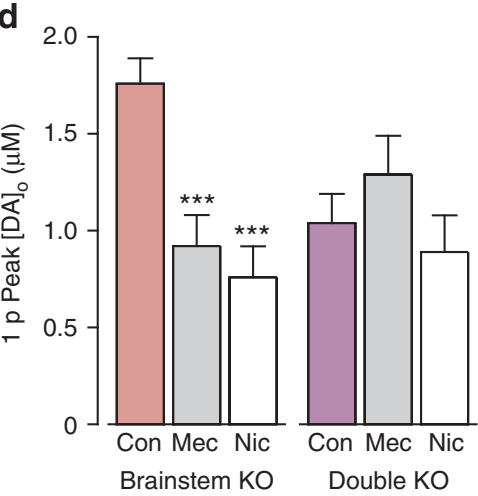

Brainstem KO

Double KO
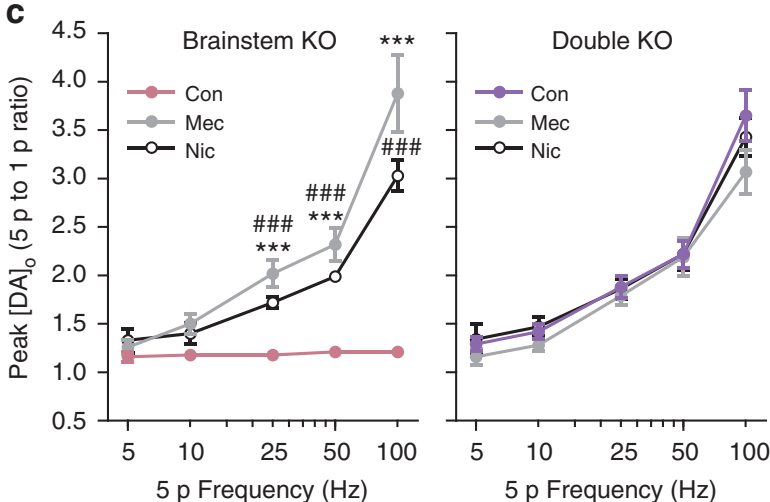

Figure 5 | Loss of brainstem-derived ACh does not affect local regulation of striatal DA release. (a-d) Voltammetric measurements of extracellular $[D A]_{\circ}$ in the CPu of striatal slices. (a) Representative single-pulse (1 p) and five-pulse (5 p) evoked [DA]。 recorded in brainstem KO and forebrain/ brainstem double $\mathrm{KO}$ mice. (b, c) Mean peak $[\mathrm{DA}]_{\text {。 }}$ evoked by $1 \mathrm{p}$ and $5 \mathrm{p}$ stimulation shows that $\mathrm{DA}$ release is not significantly altered in brainstem $\mathrm{KO}$ versus control mice (b). In double $\mathrm{KO}$ mice, there is a general suppression of DA release up to $10 \mathrm{~Hz}$, maintenance of release levels at 25 and $50 \mathrm{~Hz}$, and enhanced peak $[D A]_{0}$ at $100 \mathrm{~Hz}(\mathbf{b})\left({ }^{\star \star \star} P<0.001\right.$ versus control; unpaired $t$-test for comparison of $1 \mathrm{p}$ or two-way ANOVA with Bonferroni correction for comparison of 5 p). (c) Frequency dependence ( 5 p-to-1 p ratio) of evoked [DA]。 in brainstem and double KO mice under control conditions (con) and in the presence of the $\mathrm{nAChR}$ antagonist mecamylamine (mec; $5 \mu \mathrm{M}$ ) or a desensitizing concentration of the nAChR agonist nicotine (nic; $500 \mathrm{nM}$ ) ( ${ }^{\star \star} P<0.001 \mathrm{mec}$ versus con, $\# \# \# P<0.001$ nic versus con, two-way ANOVA with Bonferroni correction). The $1 p$-to- $5 p$ ratio in double KO mice under control conditions was indistinguishable from those seen in control mice in mec or nic ( $P>0.05$ for each frequency for either mec or nic, two-way ANOVA with Bonferroni correction). (d) $1 \mathrm{p}$ evoked $[\mathrm{DA}]_{\mathrm{o}}$ in double $\mathrm{KO}$ mice was not suppressed by either mec or nic, in contrast to brainstem $\mathrm{KO}$ mice ${ }^{\star \star \star} P<0.001$ versus con, one-way ANOVA with Dunnett's correction). Data for brainstem KOs are derived from four mice with $n=16$ recording sites in con and $n=8$ sites in each drug. Data for double forebrain/brainstem KOs are derived from four mice with $n=16$ recording sites in con, $n=7$ sites in mec and $n=9$ sites in nic. All data are means \pm s.e.m. con, control conditions; mec, mecamylamine; nic, nicotine.

activity $^{36}$. Given that striatal cholinergic interneurons can corelease glutamate $^{37}$, Guzman et al. ${ }^{36}$ argue that the lack of change in locomotor activity is because glutamate release remains intact in this VAChT KO model. On the other hand, optogenetic inhibition of cholinergic interneurons in the $\mathrm{CPu}$ or NAc, which should prevent release of both ACh and glutamate, also has no effect on spontaneous locomotor behavior ${ }^{38,39}$. It is relevant to note that immunolesions of forebrain cholinergic projection neurons with 192 IgG-saporin (which spares striatal cholinergic interneurons) also fail to produce alterations in locomotion behaviour $^{40}$.

Our studies differ from this previous body of work in several ways. First, by targeting ChAT we examined the complete and selective loss of ACh, whereas disruption of VAChT leads to the accumulation of intracellular $\mathrm{ACh}^{41}$ that could potentially result in residual cholinergic tone via non-quantal release mediated by the choline transporter ${ }^{42}$. Second, we deliberately examined motor behaviour in a novel environment, which leads to DA neuron burst firing and consequent DA release ${ }^{19,20,30,31}$. This novelty is lost in typical studies of locomotor behaviour that include an acclimation step ${ }^{43}$. Our data therefore refocus attention back on cholinergic regulation of striatal DA release as a component of motivated behaviour. The importance of these behavioural findings has been augmented by the recent demonstration that activation of striatal cholinergic interneurons directly trigger axonal DA release ${ }^{11,12}$. Our results in forebrain $\mathrm{KO}$ mice indicate that in the absence of local DA release regulation by striatal $\mathrm{ACh}$ in forebrain ChAT KO mice, the consequent absence of cholinergic gating of DA release leads to DA signalling that more faithfully reflects DA neuron activity.

The simplest explanation for the hypoactive phenotype of brainstem $\mathrm{KO}$ mice is decreased phasic activity of midbrain DA neurons ${ }^{9}$; however, other structures also receive cholinergic innervation from the PTg and LDTg, including the thalamus ${ }^{44}$. Given that the thalamus provides glutamatergic inputs to MSNs, reduction of cholinergic signalling within the thalamus could be a contributing factor to the hypoactivity phenotype observed. However, as thalamic input provides much less robust excitation of MSNs than does cortical input ${ }^{45}$, changes in thalamic activation alone should have only a minor direct effect on MSN output. Glutamatergic input from the thalamus can also activate striatal cholinergic interneurons ${ }^{11,46}$, although the net 

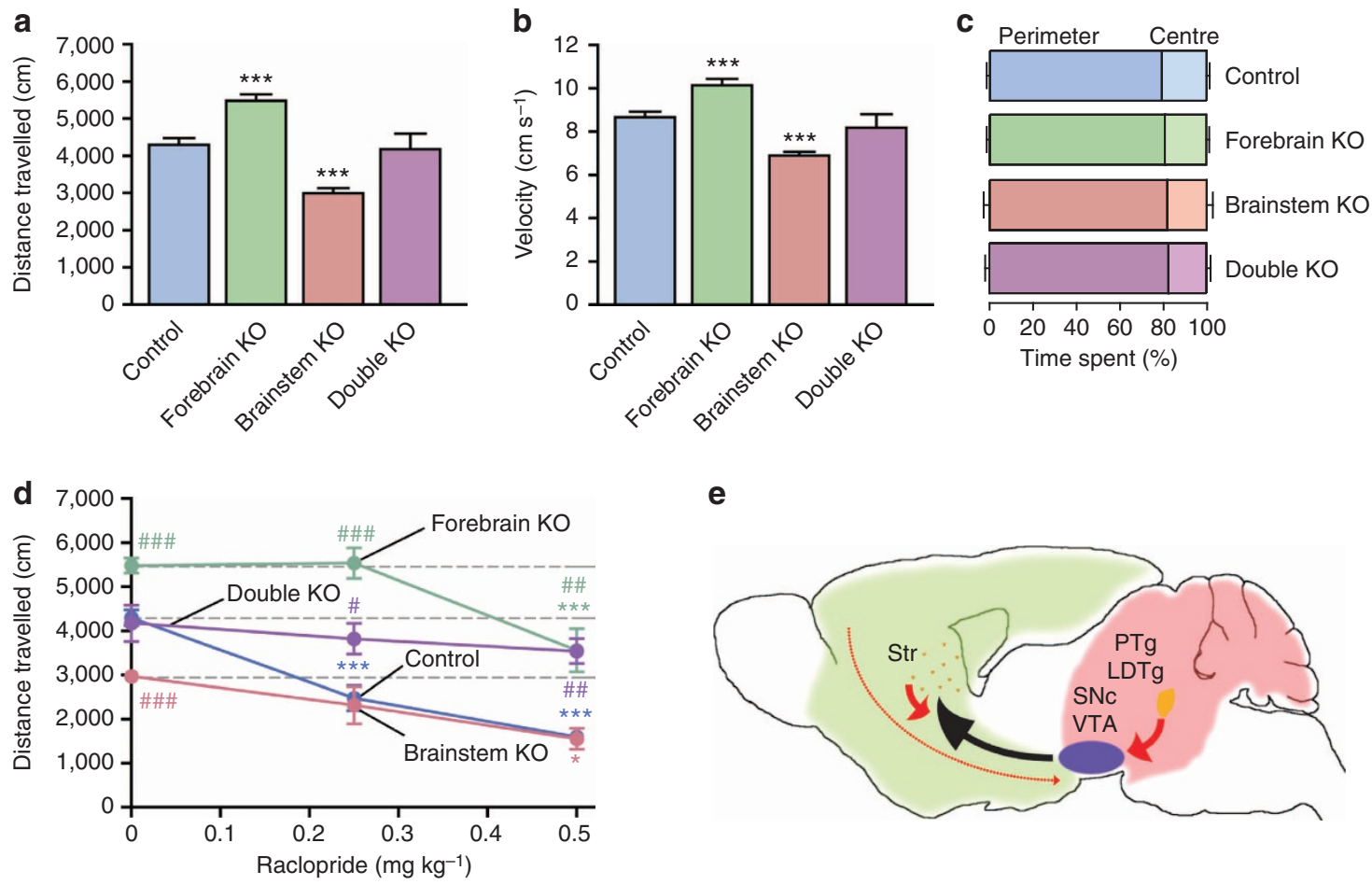

e

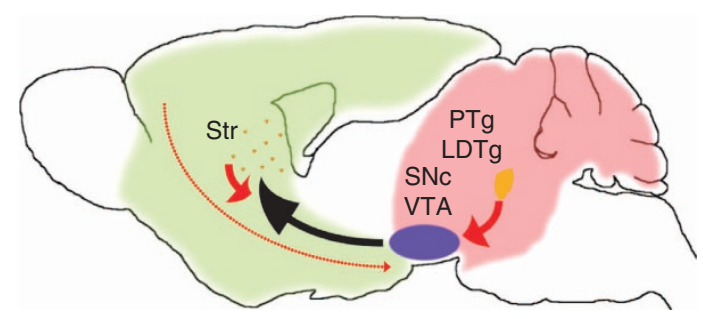

Figure 6 | Hyperactivity in forebrain ACh KO mice is normalized by D2R antagonism or by loss of brainstem ACh. (a, b) Summary of open field activity showing changes in total distance travelled per $10 \mathrm{~min}$ assay (a) and velocity of movement (b) in naive control $(n=26)$, forebrain KO ( $n=12)$, brainstem $\mathrm{KO}(n=14)$ and forebrain/brainstem double KO $(n=8)$ mice; ${ }^{\star \star \star} P<0.001$ versus control, one-way ANOVA with Dunnett's correction. (c) Loss of brain ACh does not alter anxiety-related behaviour in the open field arena. There were no significant differences in the time spent in the centre versus perimeter zones during the first $10 \mathrm{~min}$ in the arena between non-mutant control $(n=26)$, forebrain KO $(n=12)$, brainstem KO $(n=14)$ and forebrain/brainstem double KO $(n=8)$ mice; $P>0.05$ versus control, one-way ANOVA with Dunnett's correction. (d) Titration of raclopride dosage reveals the hyperdopaminergic phenotype of forebrain cholinergic mutants $(n=4-12)$ versus control $(n=5-26)$. Raclopride has little effect on locomotor activity when brainstem ACh is removed, suggesting lower D2 receptor activation in hypoactive brainstem KO mice $(n=4-14)$ than in control mice. Double KO mice exhibit a similar insensitivity to raclopride to that seen in brainstem $\mathrm{KO}$ mice $(n=6-8) .{ }^{\star} P<0.05 ;{ }^{\star \star \star} P<0.001$ versus $0 \mathrm{mg} \mathrm{kg}^{-1}$ in each mouse group, one-way ANOVA with Bonferroni correction; $\# P<0.01$; \#\# $P<0.001$ versus control mice, two-way ANOVA with Bonferroni correction. (e) Sagittal schematic depicting a model for coordinate regulation of DA release at the presynaptic level by striatal cholinergic interneurons (green territory) and at the soma by PTg/LDTg cholinergic projection neurons (red territory) as well as by descending forebrain projections from the prefrontal cortex, ventral pallidum and hippocampus (green territory). All data are means \pm s.e.m.

consequence of this on motor behaviour is difficult to predict. Thalamic activation can trigger striatal DA release via stimulation of local cholinergic interneurons and consequent activation of nAChRs on DA axons ${ }^{11,46}$, such that removal of brainstem cholinergic input to the thalamus could contribute to the hypoactivity seen in brainstem ACh $\mathrm{KO}$ mice via reduction of this pathway. On the other hand, thalamic activation of cholinergic interneurons can also decrease glutamatergic input to MSNs via mAChRs on cortical and thalamic terminals ${ }^{46,47}$, and enhance activation of indirect-pathway $\mathrm{MSNs}^{15,46,48}$, so that reduction of this process would be predicted to contribute to hyperactivity, which is opposite from what we observed in brainstem ACh $\mathrm{KO}$ mice.

In addition to the thalamus, loss of brainstem cholinergic input to other brain regions might also contribute to the observed hypoactivity phenotype. General PTg lesion does lead to hypoactivity and to increased activity of the subthalamic nucleus and $\mathrm{SN}$ pars reticulata $(\mathrm{SNr})$, however, these responses are thought to be secondary to the glutamatergic PTg inputs to SNc DA neurons ${ }^{49}$ that would not be affected by brainstem ChAT removal. Strikingly, motor behaviour is normal in double KO mice, suggesting that any deficits in DA neuron burst firing from loss of brainstem cholinergic inputs is compensated by amplification of striatal phasic-to-tonic DA signalling in the absence of local cholinergic regulation. Behavioural normalization in double KOs also argues against a primary role for thalamic drive of cholinergic interneurons and consequent DA release in exploratory behaviour in a novel environment.

The mice introduced here provide unique models to examine the role of $\mathrm{ACh}$ in a variety of behavioural contexts. Indeed, a major advantage of these mice is that they provide a reproducible and non-invasive means of selectively eliminating cholinergic activity in forebrain versus brainstem regions without loss of the cells themselves. This is important given that many of these neurons can also release other transmitters/modulators in addition to ACh that may impact brain physiology ${ }^{37}$. Thus, the selective removal of $\mathrm{ACh}$ synthesis achieved by our genetic methods provides a more specific means by which to examine the role of ACh in brain function and animal behaviour.

The present findings highlight the critical role of forebrain and brainstem cholinergic signalling in regulating exploratory motor activity, and how imbalances in brain cholinergic tone can affect pathways that converge on dopaminergic circuits. The distinct differences in DA-dependent behaviours between forebrain and brainstem ACh $\mathrm{KO}$ mice and the normalization of motor behaviour in double KOs provides novel insights into $\mathrm{ACh} / \mathrm{DA}$ interactions and the balance of ACh activities throughout the brain that is required for proper motor function. 


\section{Methods}

Mice and genotyping. Mice harbouring a conditional ('floxed') allele for ChAT were obtained as a kind gift from Dr Joshua Sanes ${ }^{21}$. Genotyping by PCR for the wild-type ChAT allele was performed with the following primers: $5^{\prime}$-CAACCGC CTGGCCCTGCCAGTCAACTCTAG- ${ }^{\prime}$ and $5^{\prime}$ - GAGGATGAAATCCTGACAG ATTCCAACAGG- $3^{\prime}$. The ChAT flox allele was genotyped by PCR using the following primers: $5^{\prime}$-TGGTTCTTTCCGCCTCAGGACTCTTCCTTT- $3^{\prime}$ and $5^{\prime}$-TAACCAAACGTAATATATGTTTGTTGGAGC- ${ }^{\prime}$. The $N k \times 2 .{ }^{2}$ Cre BAC transgenic line ${ }^{22}$, a kind gift from Dr Stewart Anderson, was genotyped using the primers $5^{\prime}$-AAGGCGGACTCGGTCCACTCCG-3' and $5^{\prime}$-TCGGATCCGCC GCATAACCAG-3'. The En1 ${ }^{\mathrm{Cre}}$ line ${ }^{28}$, a kind gift from Dr Alex Joyner, was genotyped using the primers $5^{\prime}$-GCCTTCTTCCTCTCCGCGCAC- $3^{\prime}$ and $5^{\prime}$-TCG GATCCGCCGCATAACCAG-3' (same reverse Cre primer as used with $N k \times 2.1^{\text {Cre }}$ genotyping)

All experiments used heterozygous non-mutant transgenic littermates as

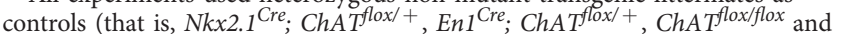
$C h A T^{f l o x} /+$ are referred to as 'control' in the main text). We used these littermate controls rather than genuine wild-type $\left(\mathrm{ChAT}^{+/+}\right)$animals to subtract out nonspecific phenotypes that might arise from the presence of the Cre allele (for example, non-specific effects of Cre recombinase expression, or genomic alterations arising from transgene insertion) or ChAT $T^{\text {flox }}$ allele (for example, potentially hypomorphic properties). It should be noted, however, that the expression pattern of ChAT mRNA as determined by in situ hybridization staining did not differ among the control genotypes. Moreover, levels of ACh should not be altered in these heterozygous control animals, as although ChAT enzymatic activity is essential for ACh production it is not the rate-limiting step, which is consistent with a lack of differences in voltammetric or behavioural data among these control groups.

All animal handling procedures were in accordance with the National Institutes of Health guidelines and were approved by the Institutional Animal Care and Use Committees of New York University School of Medicine.

In situ hybridization. To generate an antisense cRNA in situ hybridization probe specific for the region flanked by loxP sites (exons 3-4), the following primers were used to generate a PCR template for probe synthesis (T7) from a full-length mouse ChAT cDNA clone (Open Biosystems clone ID: 40129512): 5'-GACTTACC TAAGTTGCCAGTG- ${ }^{\prime}$ and ${ }^{\prime}$-AATTAATACGACTCACTATAGCTTAGCTG GTCATTGGTGT-3'. In situ hybridization with digoxigenin-labelled cRNA probes was performed essentially as previously described ${ }^{50}$. Briefly, sections $(16-20 \mu \mathrm{m}$ thick) were air dried, fixed in $4 \%$ paraformaldehyde in phosphate-buffered saline (PBS), pH $7.2\left(\mathrm{PFA} ; 10 \mathrm{~min}\right.$ at $4{ }^{\circ} \mathrm{C}$ ), treated at room temperature sequentially with $1.5 \% \mathrm{H}_{2} \mathrm{O}_{2}$ in methanol $(15 \mathrm{~min}), 0.2 \mathrm{M} \mathrm{HCl}(8 \mathrm{~min})$, proteinase $\mathrm{K}\left(10 \mu \mathrm{g} \mathrm{ml}{ }^{-1}\right.$ PBS; $5 \mathrm{~min}), 4 \% \mathrm{PFA}\left(10 \mathrm{~min}, 4^{\circ} \mathrm{C}\right)$ and acetylation buffer $(0.1 \mathrm{M}$ triethanolamine, $0.045 \mathrm{~N} \mathrm{NaOH}, 0.025 \%$ acetic anhydride), with PBS washes $(3 \times 5 \mathrm{~min})$ between each step, before overnight hybridization at $55^{\circ} \mathrm{C}(100 \mathrm{ng}$ probe per millilitre buffer: $50 \%$ formamide, $10 \%$ dextran sulphate, $1 \%$ Denhardt's solution, $250 \mathrm{\mu g} \mathrm{ml}^{-1}$ yeast tRNA, $0.3 \mathrm{M} \mathrm{NaCl}, 20 \mathrm{mM}$ Tris-HCl pH 8.0, $5 \mathrm{mM}$ EDTA, $10 \mathrm{mM} \mathrm{NaH}_{2} \mathrm{PO}_{4}, 1 \%$ sarcosyl). Following hybridization, slides were washed in saline-sodium citrate buffer $/ 50 \%$ formamide at $65^{\circ} \mathrm{C}$, treated with RNase $\left(20 \mathrm{~g} \mathrm{ml}^{-1}\right.$ in $0.5 \mathrm{M} \mathrm{NaCl}, 10 \mathrm{mM}$ Tris- $\mathrm{HCl}, \mathrm{pH}$ 7.5, $5 \mathrm{mM}$ EDTA) and incubated overnight with anti-digoxigenin Fab fragments conjugated to peroxidase (Roche; 1:500 dilution in $100 \mathrm{mM}$ maleic acid, $150 \mathrm{mM} \mathrm{NaCl}, 0.05 \%$ Tween-20, $\mathrm{pH} 7.5$, with $1 \%$ blocking reagent). Following sequential incubations with biotinyl-tyramide and streptavidin-alkaline phosphatase, signal was visualized with standard nitro-blue tetrazolium and 5-bromo-4-chloro- $3^{\prime}$-indolyl phosphate histochemistry. Hybridized sections were counterstained with Fast Red (Vector Labs), dehydrated, and coverslipped with Permount before imaging with a Zeiss Axioplan brightfield microscope.

Voltammetric recording of DA release in striatal slices. Procedures for preparing striatal slices and voltammetric recording of striatal DA release were according to those described previously ${ }^{13,51-53}$. Coronal forebrain slices $(350 \mu \mathrm{m}$ thick) were prepared from transgenic mice and their non-mutant control littermates (3-5 months of age) using a VT200S vibrating blade microtome (Leica Microsystems), then maintained in HEPES-buffered artificial cerebrospinal fluid $(\mathrm{aCSF})$ at room temperature for at least $1 \mathrm{~h}$ before experimentation. Male mice were used for recordings in $\mathrm{CPu}$ whereas females were used for measurements in the NAc.

For recording, slices were transferred to a submersion chamber (Warner Instruments LLC) maintained at $32^{\circ} \mathrm{C}$ and superfused at $1.2 \mathrm{ml} \mathrm{min}^{-1}$ with bicarbonate-buffered aCSF containing (in mM): $\mathrm{NaCl}$ (124); $\mathrm{KCl}$ (3.7); $\mathrm{NaHCO}_{3}$ (26); $\mathrm{MgSO}_{4}$ (1.3); $\mathrm{KH}_{2} \mathrm{PO}_{4}$ (1.3); glucose (10); and $\mathrm{CaCl}_{2}$ (2.4), and saturated with $95 \% \mathrm{O}_{2} / 5 \% \mathrm{CO}_{2}$. After an equilibration period of at least $30 \mathrm{~min}$, fast-scan cyclic voltammetry with carbon-fibre microelectrodes ( $7 \mu \mathrm{m}$ diameter, 30-70 $\mu \mathrm{m}$ length, manufactured in-house) was used to monitor evoked $[\mathrm{DA}]_{\mathrm{o}}$. Release of DA was elicited in either the dorsolateral portion of the striatum, the NAc core or the NAc shell using concentric bipolar stimulating electrodes placed on the surface of the slice ventromedially to the carbon fibre recording electrode.

Voltammetric measurements were made using a Millar voltammeter (available by special request to Dr Julian Millar at St Bartholomew's and the Royal London
School of Medicine and Dentistry, University of London, UK). Scan range was $-0.7 \mathrm{~V}$ to $+1.3 \mathrm{~V}$ (versus $\mathrm{Ag} / \mathrm{AgCl}$ ), scan rate was $800 \mathrm{~V} \mathrm{~s}^{-1}$, and the sampling interval was $100 \mathrm{~ms}$. Data were acquired using a DigiData 200B A/D board controlled by Clampex 7.0 software (Molecular Devices). Released DA was identified according to voltammograms showing the single oxidation and reduction peak potentials that characterize the voltammetric signature of DA. To quantify evoked $[\mathrm{DA}]_{\mathrm{o}}$, electrodes were calibrated with known concentrations of DA at $32^{\circ} \mathrm{C}$ after each experiment in aCSF, in the presence and absence of each drug used during a given experiment.

To decrease recording bias, the experimental design for the $\mathrm{CPu}$ typically involved sampling $[D A]_{0}$ in four recording sites of each striatal slice; two sites in control conditions and two sites in either mecamylamine ( $5 \mu \mathrm{M}$, Sigma) or nicotine ( $500 \mathrm{nM}$, Sigma). Two slices (one for each drug) were examined per mouse during an experimental day. In each recording site, release of DA was evoked by singlepulse ( $1 \mathrm{p}$ ) stimulation ( 0.4 to $0.6 \mathrm{~mA}$ amplitude, $0.1 \mathrm{~ms}$ duration) and by stimulation with five pulses (5 p) at $5,10,25,50$ and $100 \mathrm{~Hz}$, applied at $5 \mathrm{~min}$ intervals. Stimulation frequencies were presented in either an ascending or descending order in the first control recording site and reversed for the second control site. The drug (either mecamylamine or nicotine) was then applied to the superfusing aCSF for at least 10-15 min before these patterns of stimulation were repeated for recording sites in the presence of drug. Experiments in the NAc core and shell were conducted in a similar manner to those described for the $\mathrm{CPu}$ only with two to four recording sites sampled in each NAc subregion of a single coronal slice in the absence of drugs.

Open field behavioural assays. Open field video recordings were performed in a $40 \times 40 \mathrm{~cm}$ white plexiglass arena using Noldus Ethovision Pro 3.1 tracking and analysis software. Naive experimental and control littermate male and female mice between 6 and 10 weeks of age were transferred in their respective home cages to the testing room at least $30 \mathrm{~min}$ before being placed in the clean arena. The first $10 \mathrm{~min}$ of activity were recorded for each mouse. We excluded one forebrain KO animal from the statistical analysis due to extreme hyperactivity. Raclopride (Sigma) in PBS was administered at the doses indicated by intraperitoneal injection $15 \mathrm{~min}$ before recording of animals in the open field arena.

Data analysis. Voltammetric DA recording: data are expressed as mean \pm s.e.m. where $n$ indicates the number of recording sites in one to three slices from three to five mice per group and illustrated as either absolute $[D A]_{0}$ or the ratio of $5 \mathrm{p}$ evoked $[\mathrm{DA}]_{\mathrm{o}}$ to $1 \mathrm{p}$. Open field activity recordings: data are expressed as mean \pm s.e.m., where $n$ indicates the number of mice, and illustrated as total distance travelled and velocity of movement. Data were analysed using GraphPad Prism Software. Significance of differences was assessed using either an unpaired $t$-test, one-way ANOVA or two-way ANOVA as appropriate. Significance was considered to be $P<0.05$.

\section{References}

1. Redgrave, P., Gurney, K. \& Reynolds, J. What is reinforced by phasic dopamine signals? Brain Res. Rev. 58, 322-339 (2008).

2. Gerfen, C. R. \& Surmeier, D. J. Modulation of striatal projection systems by dopamine. Annu. Rev. Neurosci. 34, 441-466 (2011).

3. Schultz, W. Potential vulnerabilities of neuronal reward, risk, and decision mechanisms to addictive drugs. Neuron 69, 603-617 (2011).

4. Lester, D. B., Rogers, T. D. \& Blaha, C. D. Acetylcholine-dopamine interactions in the pathophysiology and treatment of CNS disorders. CNS Neurosci. Ther. 16, 137-162 (2010).

5. Grenhoff, J., Aston-Jones, G. \& Svensson, T. H. Nicotinic effects on the firing pattern of midbrain dopamine neurons. Acta Physiol. Scand. 128, 351-358 (1986).

6. Floresco, S. B., West, A. R., Ash, B., Moore, H. \& Grace, A. A. Afferent modulation of dopamine neuron firing differentially regulates tonic and phasic dopamine transmission. Nat. Neurosci. 6, 968-973 (2003).

7. Mena-Segovia, J., Winn, P. \& Bolam, J. P. Cholinergic modulation of midbrain dopaminergic systems. Brain Res. Rev. 58, 265-271 (2008).

8. Drenan, R. M. et al. In vivo activation of midbrain dopamine neurons via sensitized, high-affinity alpha 6 nicotinic acetylcholine receptors. Neuron $\mathbf{6 0}$, 123-136 (2008).

9. Lodge, D. J. \& Grace, A. A. The laterodorsal tegmentum is essential for burst firing of ventral tegmental area dopamine neurons. Proc. Natl Acad. Sci. USA 103, 5167-5172 (2006).

10. Zhou, F. M., Liang, Y. \& Dani, J. A. Endogenous nicotinic cholinergic activity regulates dopamine release in the striatum. Nat. Neurosci. 4, 1224-1229 (2001)

11. Threlfell, S. et al. Striatal dopamine release is triggered by synchronous activity in cholinergic interneurons. Neuron 75, 58-64 (2012).

12. Cachope, R. et al. Selective activation of cholinergic interneurons enhances accumbal phasic dopamine release: setting the tone for reward processing. Cell Reports 2, 1-9 (2012).

13. Rice, M. E. \& Cragg, S. J. Nicotine amplifies reward-related dopamine signals in striatum. Nat. Neurosci. 7, 583-584 (2004). 
14. Zhang, H. \& Sulzer, D. Frequency-dependent modulation of dopamine release by nicotine. Nat. Neurosci. 7, 581-582 (2004).

15. Oldenburg, I. A. \& Ding, J. B. Cholinergic modulation of synaptic integration and dendritic excitability in the striatum. Curr. Opin. Neurobiol. 21, 425-432 (2011).

16. Wang, J. Q. \& McGinty, J. F. Intrastriatal injection of a muscarinic receptor agonist and antagonist regulates striatal neuropeptide mRNA expression in normal and amphetamine-treated rats. Brain Res. 748, 62-70 (1997).

17. Grace, A. A., Floresco, S. B., Goto, Y. \& Lodge, D. J. Regulation of firing of dopaminergic neurons and control of goal-directed behaviors. Trends Neurosci. 30, 220-227 (2007)

18. Morikawa, H. \& Paladini, C. A. Dynamic regulation of midbrain dopamine neuron activity: intrinsic, synaptic, and plasticity mechanisms. Neuroscience 198, 95-111 (2011)

19. Giros, B., Jaber, M., Jones, S. R., Wightman, R. M. \& Caron, M. G. Hyperlocomotion and indifference to cocaine and amphetamine in mice lacking the dopamine transporter. Nature 379, 606-6120 (1996).

20. Gainetdinov, R. R. et al. Role of serotonin in the paradoxical calming effect of psychostimulants on hyperactivity. Science 283, 397-401 (1999).

21. Misgeld, T. et al. Roles of neurotransmitter in synapse formation: development of neuromuscular junctions lacking choline acetyltransferase. Neuron 36, 635-648 (2002).

22. Xu, Q., Tam, M. \& Anderson, S. A. Fate mapping Nkx2.1-lineage cells in the mouse telencephalon. J. Comp. Neurol. 506, 16-29 (2008).

23. Zhang, T. et al. Dopamine signaling differences in the nucleus accumbens and dorsal striatum exploited by nicotine. J. Neurosci. 29, 4035-4043 (2009).

24. Threlfell, S. et al. Striatal muscarinic receptors promote activity dependence of dopamine transmission via distinct receptor subtypes on cholinergic interneurons in ventral versus dorsal striatum. J. Neurosci. 30, 3398-3408 (2010).

25. Exley, R., McIntosh, J. M., Marks, M. J., Maskos, U. \& Cragg, S. J. Striatal $\alpha 5$ nicotinic receptor subunit regulates dopamine transmission in dorsal striatum. J. Neurosci. 32, 2352-2356 (2012).

26. Patel, J., Trout, S. J. \& Kruk, Z. L. Regional differences in evoked dopamine efflux in brain slices of rat anterior and posterior caudate putamen. Naunyn Schmiedebergs Arch. Pharmacol. 346, 267-276 (1992).

27. Trout, S. J. \& Kruk, Z. L. Differences in evoked dopamine efflux in rat caudate putamen, nucleus accumbens and tuberculum olfactorium in the absence of uptake inhibition: influence of autoreceptors. Brit. J. Pharmacol. 106, 452-458 (1992).

28. Kimmel, R. A. et al. Two lineage boundaries coordinate vertebrate apical ectodermal ridge formation. Genes Dev. 14, 1377-1389 (2000).

29. Sombers, L. A., Beyene, M., Carelli, R. M. \& Wightman, R. M. Synaptic overflow of dopamine in the nucleus accumbens arises from neuronal activity in the ventral tegmental area. J. Neurosci. 29, 1735-1742 (2009).

30. Rebec, G. V., Grabner, C. P., Johnson, M., Pierce, R. C. \& Bardo, M. T. Transient increases in catecholaminergic activity in medial prefrontal cortex and nucleus accumbens shell during novelty. Neuroscience 76, 707-714 (1997).

31. Marinelli, M. \& White, F. J. Enhanced vulnerability to cocaine selfadministration is associated with elevated impulse activity of midbrain dopamine neurons. J. Neurosci. 20, 8876-8885 (2000).

32. Koepp, M. J. et al. Evidence for striatal dopamine release during a video game. Nature 393, 266-268 (1998).

33. Egerton, A. et al. The dopaminergic basis of human behaviors: A review of molecular imaging studies. Neurosci. Biobehav. Rev. 33, 1109-1132 (2009).

34. Watabe-Uchida, M., Zhu, L., Ogawa, S. K., Vamanrao, A. \& Uchida, N. Whole-brain mapping of direct inputs to midbrain dopamine neurons. Neuron 74, 858-873 (2012).

35. Kaneko, S. et al. Synaptic integration mediated by striatal cholinergic interneurons in basal ganglia function. Science 289, 633-637 (2000).

36. Guzman, M. S. et al. Elimination of the vesicular acetylcholine transporter in the striatum reveals regulation of behaviour by cholinergic-glutamatergic co-transmission. PLoS Biol. 9, e1001194 (2011).

37. Higley, M. J. et al. Cholinergic interneurons mediate fast VGluT3-dependent glutamatergic transmission in the striatum. PLoS One 6, e19155 (2011).

38. Witten, I. B. et al. Cholinergic interneurons control local circuit activity and cocaine conditioning. Science 330, 1677-1681 (2010).
39. English, D. F. et al. GABAergic circuits mediate the reinforcement-related signals of striatal cholinergic interneurons. Nat. Neurosci. 15, 123-130 (2012).

40. Leanza, G., Nilsson, O. G., Nikkhah, G., Wiley, R. G. \& Bjorklund, A. Effects of neonatal lesions of the basal forebrain cholinergic system by 192 immunoglobulin G-saporin: biochemical, behavioural and morphological characterization. Neuroscience 74, 119-141 (1996).

41. Martins-Silva, C. et al. Novel strains of mice deficient for the vesicular acetylcholine transporter: insights on transcriptional regulation and control of locomotor behavior. PLoS One 6, e17611 (2011).

42. Chavez, J., Vargas, M. H., Cruz-Valderrama, J. E. \& Montano, L. M. Non-quantal release of acetylcholine in guinea-pig airways: role of choline transporter. Exp. Physiol. 96, 460-467 (2011).

43. Pierce, R. C. \& Kalivas, P. W. Locomotor behavior. Curr. Protoc. Neurosci. Chapter 8 (2007)

44. Hallanger, A. E., Levey, A. I., Lee, H. J., Rye, D. B. \& Wainer, B. H. The origins of cholinergic and other subcortical afferents to the thalamus in the rat. J. Comp. Neurol. 262, 105-124 (1987).

45. Ding, J., Peterson, J. D. \& Surmeier, D. J. Corticostriatal and thalamostriatal synapses have distinctive properties. J. Neurosci. 28, 6483-6492 (2008).

46. Ding, J. B., Guzman, J. N., Peterson, J. D., Goldberg, J. A. \& Surmeier, D. J. Thalamic gating of corticostriatal signaling by cholinergic interneurons. Neuron 67, 294-307 (2010).

47. Pakhotin, P. \& Bracci, E. Cholinergic interneurons control the excitatory input to the striatum. J. Neurosci. 27, 391-400 (2007).

48. Shen, W. et al. Cholinergic modulation of Kir2 channels selectively elevates dendritic excitability in striatopallidal neurons. Nat. Neurosci. 10, 1458-1466 (2007).

49. Breit, S., Lessmann, L., Benazzouz, A. \& Schulz, J. B. Unilateral lesion of the pedunculopontine nucleus induces hyperactivity in the subthalamic nucleus and substantia nigra in the rat. Eur. J. Neurosci. 22, 2283-2294 (2005).

50. Batista-Brito, R., Machold, R., Klein, C. \& Fishell, G. Gene expression in cortica interneuron precursors is prescient of their mature function. Cereb. Cortex 18, 2306-2317 (2008).

51. Patel, J. C., Witkovsky, P., Avshalumov, M. V. \& Rice, M. E. Mobilization of calcium from intracellular stores facilitates somatodendritic dopamine release. J. Neurosci. 29, 6568-6579 (2009).

52. Bao, L., Patel, J. C., Walker, R. H., Shashidharan, P. \& Rice, M. E. Dysregulation of striatal dopamine release in a mouse model of dystonia. J. Neurochem. 114, 1781-1791 (2010).

53. Patel, J. C. \& Rice, M. E. Monitoring axonal and somatodendritic dopamine release using fast-scan cyclic voltammetry in slices. in Dopamine: Methods and Protocols, Series: Methods in Molecular Biology, Vol. 964 (ed Kabbani, N.) Ch. 15, 243-273 (Springer Protocols, Humana Press, 2013; in press).

\section{Acknowledgements}

This work was supported by Alzheimer's Association grant 90664 (R.P.M.; awarded to Dr B. Rudy), NIH R01 grant MH068469 (R.P.M.; awarded to Dr G. Fishell), FRSQ training award (E.R.), NIH/NINDS R01 grant NS036362 (M.E.R.) and the Attilio and Olympia Ricciardi Research Fund (M.E.R.).

\section{Author contributions}

R.P.M. designed, generated and genotyped the mice, and performed the histological analyses. J.C.P. and M.E.R. designed, performed and analysed the DA release experiments. R.P.M., E.R. and J.C.P. designed, performed and analysed the behavioural experiments. All authors interpreted the data and wrote the manuscript.

\section{Additional information}

Competing financial interests: The authors declare no competing financial interests.

Reprints and permission information is available online at http://npg.nature.com/ reprintsandpermissions/

How to cite this article: Patel, J.C. et al. Opposing regulation of dopaminergic activity and exploratory motor behavior by forebrain and brainstem cholinergic circuits. Nat. Commun. 3:1172 doi: 10.1038/ncomms2144 (2012). 